\title{
Thermal resistance of steel energy screw piles
}

\author{
Luis A. Bandeira Neto, Nikolas Makasis and Guillermo A. Narsilio ${ }^{1}$ \\ ${ }^{1}$ The University of Melbourne, Department of Infrastructure Engineering, Engineering Block B 208, Parkville, VIC 3010, Australia, +61 \\ (3) 83444659
}

\section{Introduction}

The use of energy structures as underground heat exchangers in ground source heat pump (GSHP) systems is key for reducing the system's capital costs ( $\mathrm{Lu} \&$ Narsilio, 2019). Energy piles lead the way by being most studied (and therefore, the most utilised) energy structure. However, most studies to date have focused on cylindrical concrete piles, and less attention have been given to other pile foundation solutions that can be thermally activated (Loveridge, McCartney, Narsilio, \& Sanchez, 2020). Screw piles are prefabricated supporting structures composed of a steel tube and screw elements, which can be thermally activated by inserting a high-density polyethylene (HDPE) pipe "U-loop" inside the steel tube. In order to enhance the heat exchange, the tube is backfilled with grout or other material as typically done in boreholes. Different energy pile solutions that also uses screw piles are presented in the literature (Huang et al., 2019). However, the effect of its steel components on thermal yield requires further investigation. Due to its better thermal conductivity, steel is expected to improve the pile thermal performance. This study uses a numerical model validated against a Thermal Response Test (TRT) undertaken on an energy screw pile to quantify the effects of the pile diameter and steel wall thickness on its thermal response.

\section{Methodology, Results and Discussion}

A TRT was undertaken on an energy screw pile built in Melbourne, Australia, and a three-dimensional finite element model developed in COMSOL Multiphysics was validated against its results, as summarized in Figure 1. Details on key governing equations of the model can be found in Bidarmaghz (2014) and Makasis (2019) while details of the testing can be found in Bandeira Neto et. al. (2022). The thermal properties of the backfilling grout were obtained by using a needle probe.

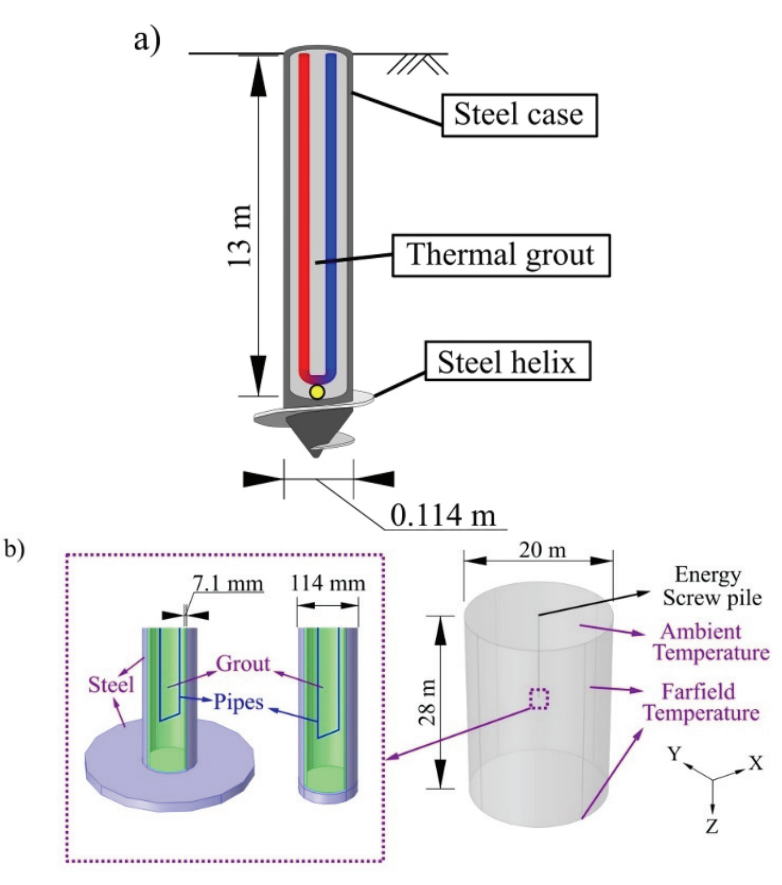

Fig. 1. Energy screw pile (a), and finite element model geometry and boundary conditions (b).

The model was calibrated by simulating the TRT using the recorded heating power as an input and adjusting the soil thermal conductivity $(\lambda \mathrm{g})$. The average fluid temperature over time obtained from the model was then compared to the experimental results by calculating the resulting Root Mean Square Error (RMSE). Two different versions of the model were used: one with the screw pile steel components (steel wall and screw, the "complete" model), and another considering only the grout (the "simple" model, without a steel wall or screw). Figure 2 presents the resulting RMSE for each $\lambda \mathrm{g}$ value trialed in each model. The complete model results suggest a value of $\lambda \mathrm{g}=1.1 \mathrm{~W} / \mathrm{m}$ (that with the lowest RMSE), slightly lower than the results for the simple model $(\lambda \mathrm{g}=$ $1.3 \mathrm{~W} /(\mathrm{mK}))$. The $0.2 \mathrm{~W} /(\mathrm{mK})$ difference is likely due to the superior thermal conductivity of the screw pile steel

\footnotetext{
* Corresponding author: narsilio@,unimelb.edu.au
} 
wall. The lowest overall RMSE value was obtained using the complete model, which is expected since it is closer to the experiment conditions than the simple model.

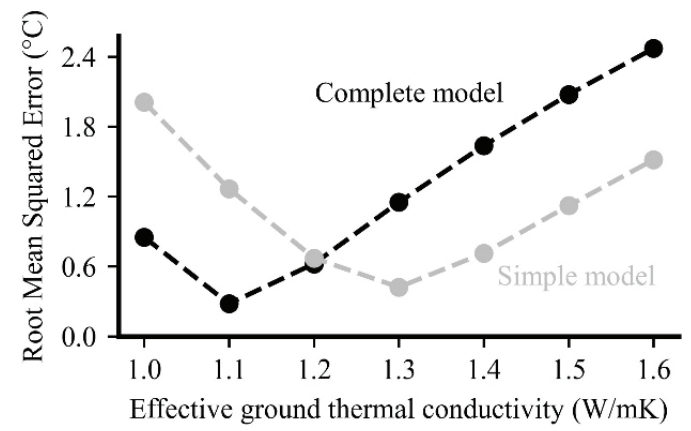

Fig. 2. Model calibration

The heat exchange inside the pile is characterized by the pile thermal resistance $(\mathrm{Rb})$, which can be determined numerically as:

$$
R_{b}=\frac{H\left(\overline{T_{f}}-\overline{T_{b}}\right)}{Q}
$$

where $\mathrm{H}$ is the heat exchanger length (pile depth), $\mathrm{Q}$ is the power rate, and $\mathrm{T}_{\mathrm{f}}$ and $\mathrm{T}_{\mathrm{b}}$ are the mean temperature values from the circulating fluid and the pile/borehole wall, respectively. The $\mathrm{R}_{\mathrm{b}}$ value varies with time, however it becomes stable when time is larger than $55 r_{b}^{2} / \alpha_{g}$, where $r_{b}$ is the pile radius and $\alpha_{\mathrm{g}}$ is the ground thermal diffusivity.

The $R_{b}$ can be used to investigate the influence of the steel components. The "complete" model was used to quantify the effects of the screw pile diameter and the steel wall thickness on $\mathrm{Rb}$. The wall thickness was treated as a percentage of the pile radius for comparison between different diameters. In order to ensure that a stable $\mathrm{Rb}$ value is achieved on all scenarios, a six day TRT was simulated. The heating power was set to be $650 \mathrm{~W}$ and the top boundary condition was switched from ambient temperature to insulation (Figure 1). The results confirm what was observed in the model calibration, showing a reduction of the $\mathrm{Rb}$ value as the percentage of steel in the pile increases (Figure 3). The drop in Rb is fairly constant through the diameters analyzed: $0.03(\mathrm{~m} \cdot \mathrm{K}) / \mathrm{W}$ difference from the simple model with $0 \%$ of steel to the model with $25 \%$ of steel. The reduction is less significant for larger diameter piles as they have a higher $\mathrm{Rb}$. The reason behind it is the constant pipe spacing; therefore, the pipes are further from the steel in the larger piles and the pipeto-pipe thermal resistance remains constant. The $\mathrm{Rb}$ drop rate is rather small, $0.012(\mathrm{~m} \cdot \mathrm{K}) / \mathrm{W}$ per $10 \%$ increase of steel. This is equivalent to a $0.6{ }^{\circ} \mathrm{C}$ difference for every $50 \mathrm{~W} / \mathrm{m}$ of thermal energy injected in or extracted from the pile. Increasing the pipe spacing when possible (e.g., larger diameters) would reduce the pipe-to-pipe thermal resistance and better utilize the benefits of the good thermal properties of the steel.
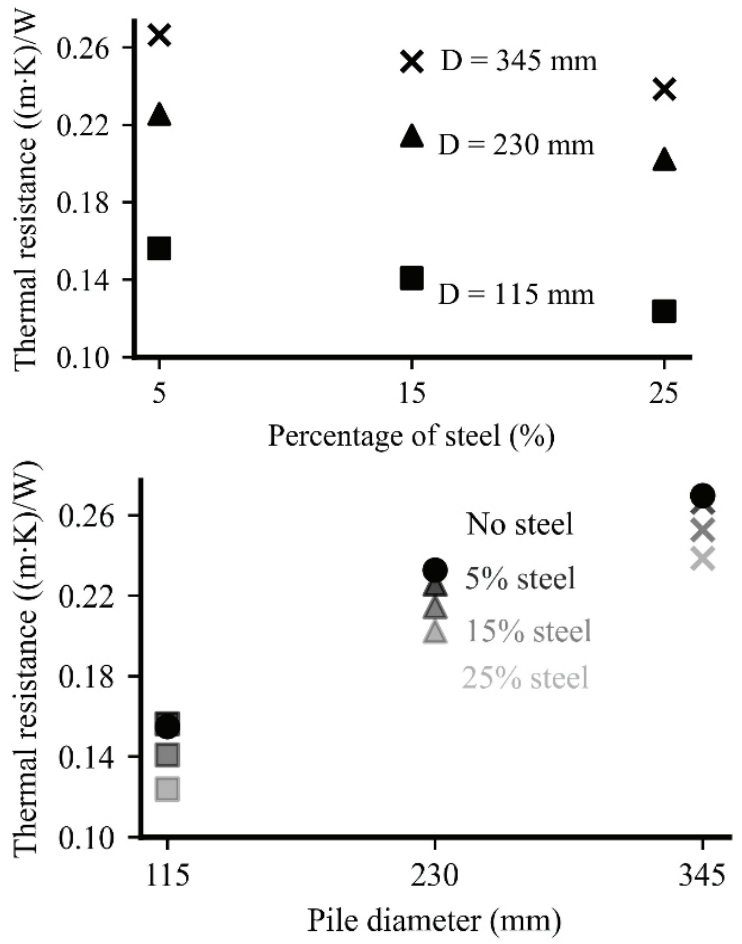

Fig. 3. Effect of screw pile steel thickness and pile diameter on thermal resistance $\mathrm{R}_{\mathrm{b}}$.

\section{References}

1. Bandeira Neto, L., Narsilio, G., Makasis, N., Choudhary, R. \& Carden, Y. (2022). Thermal response of energy screw piles connected in series. Géotechnique. Submitted for publication.

2. Bidarmaghz, A. (2014). 3D numerical modelling of vertical ground heat exchangers. Thesis $(\mathrm{PhD})$ The University of Melbourne, Melbourne, Australia.

3. Huang, J., McCartney, J. S., Perko, H., Johnson, D., Zheng, C., \& Yang, Q. (2019). A novel energy pile: The thermo-syphon helical pile. Applied Thermal Engineering, 159, 113882.

4. Loveridge, F., McCartney, J.S., Narsilio, G., \& Sanchez, M. (2020). Energy geostructures: A review of analysis approaches, in situ testing \& model experiments. Geom Energy \& Env, 22, 100173.

5. Lu, Q., \& Narsilio, G. A. (2019). Cost effectiveness of energy piles in residential dwellings in Australia. Current Trends in Civil \& Structural Engineering, 3 (3).

6. Makasis, N. (2019). Further understanding GSHP system design using FEM and ML techniques. Thesis $(\mathrm{PhD})$ The University of Melbourne, Melbourne, Australia. 